Article

\title{
Breast Cancer Resistance Protein (BCRP/ABCG2) Inhibits Extra Villous Trophoblast Migration: The Impact of Bacterial and Viral Infection
}

\author{
Phetcharawan Lye ${ }^{1}$, Enrrico Bloise ${ }^{1,2, *}$, Lubna Nadeem ${ }^{3}$, Chun Peng ${ }^{4}$, William Gibb ${ }^{5,6}$, \\ Tania M. Ortiga-Carvalho ${ }^{7}$, Stephen J. Lye ${ }^{1,3,8,9}$ and Stephen G. Matthews ${ }^{1,3,8,9}$ \\ 1 Department of Physiology, University of Toronto, Toronto, ON M5S 1A8, Canada; tlye@lunenfeld.ca (P.L.); \\ lye@lunenfeld.ca (S.J.L.); Stephen.Matthews@utoronto.ca (S.G.M.) \\ 2 Department of Morphology, Federal University of Minas Gerais, Belo Horizonte 31270-901, Brazil \\ 3 Lunenfeld-Tanenbaum Research Institute, Mount Sinai Hospital, Toronto, ON M5G 1X5, Canada; \\ nadeem@lunenfeld.ca \\ 4 Department of Biology, York University, Toronto, ON M3J 1P3, Canada; cpeng@yorku.ca \\ 5 Department of Obstetrics \& Gynaecology, University of Ottawa, Ottawa, ON K1H 8L6, Canada; \\ william.gibb@uottawa.ca \\ 6 Department of Cellular \& Molecular Medicine, University of Ottawa, Ottawa, ON K1H 8M5, Canada \\ 7 Laboratory of Translational Endocrinology, Biophysics Institute Carlos Chagas Filho, Federal University of \\ Rio de Janeiro, Rio de Janeiro 21941-902, Brazil; taniaort@biof.ufrj.br \\ 8 Department of Obstetrics \& Gynaecology, University of Toronto, Toronto, ON M5G 1E2, Canada \\ 9 Department of Medicine, Faculty of Medicine, University of Toronto, Toronto, ON M5S 1A8, Canada \\ * Correspondence: ebloise@icb.ufmg.br; Tel.: +55-31-3409-2783
}

Received: 26 August 2019; Accepted: 24 September 2019; Published: 26 September 2019

\begin{abstract}
Extravillous trophoblasts (EVT) migration into the decidua is critical for establishing placental perfusion and when dysregulated, may lead to pre-eclampsia (PE) and intrauterine growth restriction (IUGR). The breast cancer resistance protein (BCRP; encoded by $A B C G 2$ ) regulates the fusion of cytotrophoblasts into syncytiotrophoblasts and protects the fetus from maternally derived xenobiotics. Information about BCRP function in EVTs is limited, however placental exposure to bacterial/viral infection leads to BCRP downregulation in syncitiotrophoblasts. We hypothesized that BCRP is involved in the regulation of EVT function and is modulated by infection/inflammation. We report that besides syncitiotrophoblasts and cytotrophoblasts, BCRP is also expressed in EVTs. BCRP inhibits EVT cell migration in HTR8/SVneo (human EVT-like) cells and in human EVT explant cultures, while not affecting cell proliferation. We have also shown that bacterial-lipopolysaccharide (LPS) — and viral antigens — single stranded RNA (ssRNA) — have a profound effect in downregulating $A B C G 2$ and BCRP levels, whilst simultaneously increasing the migration potential of EVT-like cells. Our study reports a novel function of BCRP in early placentation and suggests that exposure of EVTs to maternal infection/inflammation could disrupt their migration potential via the downregulation of BCRP. This could negatively influence placental development/function, contribute to existing obstetric pathologies, and negatively impact pregnancy outcomes and maternal/neonatal health.
\end{abstract}

Keywords: Breast cancer resistance protein (BCRP/ABCG2); extra villous trophoblast; first trimester placenta; migration; infection

\section{Introduction}

The placenta supports the growth and development of the fetus and is paramount to a successful pregnancy [1]. A critical stage of early placental development is the proliferation and differentiation of 
cytotrophoblasts (CT) into extravillous trophoblasts (EVTs). CTs originating at the tips of the chorionic villi first grow and establish cell columns before differentiation. The resulting EVTs invade the maternal uterine tissues either through the decidualized endometrium into the inner myometrium (interstitial) or through the lumen of the uterine spiral arteries against the blood flow (endovascular) [2-4].

While appropriate migration of EVT is essential for a successful pregnancy, the maternal decidua maintains tight control over EVT migration through paracrine signaling. Insufficient invasion can result in poor placentation and can lead to preeclampsia (PE), intrauterine growth restriction (IUGR), and other serious obstetric complications [5]. Conversely, uncontrolled EVT migration/invasion can lead to the deeper penetration of trophoblasts into the myometrium rather than decidua basalis (placenta acreta) [6] or even through the uterus, affecting the surrounding organs (placenta percreta) [7], resulting in maternal/fetal morbidity and mortality. Further, in certain circumstances, uncontrolled trophoblast proliferation and invasion can lead to choriocarcinoma [8].

The transmembrane efflux transporter, breast cancer resistance protein (BCRP, encoded by ABCG2 gene), belongs to the ATP-binding cassette (ABC) transporter superfamily and is primarily localized to the apical brush-border membrane of the syncytiotrophoblast (ST) barrier [9]. BCRP regulates CT fusion into ST and provides embryo/fetal protection from drugs and environmental toxins that are present in the maternal circulation. In STs, BCRP prevents the transfer of a number of drugs from the maternal to the fetal circulation and is, therefore, considered an important fetal "gatekeeper" throughout pregnancy [9].

We have previously reported that human placental BCRP expression increases with advancing gestation and peaks at term [10,11]. Importantly, viral and bacterial challenges or pathological inflammatory states alter placental BCRP expression differently. Lipopolysaccharide (LPS; modelling bacterial infection) decreased ABCG2 and BCRP expression in first trimester human placental explants (but not in third trimester explants). Whereas, polyinosinic:polycytidylic acid (poly(I:C) (a double-stranded viral antigen) did not induce changes in BCRP expression [12]. In sharp contrast, the placenta from preterm pregnancies complicated by chorioamnionitis exhibited increased $A B C G 2$ and BCRP expression [13]. This indicates that the nature (source) and timing (gestational age) of infection/inflammation determines the positive or negative effects on the regulation of BCRP expression and consequently the potential fetal exposure to harmful BCRP substrates.

ABCG2 and BCRP expression are elevated in stem cells and cancer cells [14-17]. While BCRP is a membrane efflux protein, its role in regulating cancer cell function (cell proliferation, migration/invasion) has also been established. Studies have shown that BCRP induces cancer cell proliferation $[14,18]$ and migration/invasion.

Together, these data suggest that infection and inflammation can modulate the expression of $A B C G 2$ and BCRP in placental trophoblasts. During early gestation, altered levels of BCRP may affect the migration and invasion potential of these cells, thereby causing pregnancy complications, though to date, no studies have tested this hypothesis. Given the relatively high incidence of bacterial and viral infections during early human pregnancy [19] and its impact on BCRP expression, we determined the role of $A B C G 2$ and BCRP in modulating the migration potential of EVTs, which is critical for the establishment of placentation in early pregnancy. Further, we determined the impact of bacterial (mimicked by LPS) or viral (mimicked by single stranded RNA, ssRNA) infection on these processes.

\section{Materials and Methods}

\subsection{Ethical Approval}

Healthy first trimester human placental tissue was collected at 7-10 weeks of pregnancy by the Research Centre for Women's and Infants' Health Bio Bank program at Sinai Health System after written informed consent (process $n \# 26573$ ) and in adherence with the policies of the Sinai Health System and the University of Toronto Research Ethics Board. 


\subsection{Human Placental Explant Culture}

First trimester human placentae (6 to 7 weeks) from the elective termination of singleton pregnancies were used to set up the extravillous explant culture as described earlier [20]. Briefly, small clusters of 2 to 3 column cytotrophoblasts (CCT) villi presenting high vascularization and clear white tips were excised under the dissecting microscope. Tips of the villi were cleared to expose CCT stem cells, which were gently spread on the matrigel $(200 \mu \mathrm{L}$ per insert of phenol red free, Becton Dickinson, Bedford, MA, USA) coated transwell inserts (Millipore Corp., Billerica, MA, USA) in a 24-well culture plate. Serum free culture medium ( $400 \mu \mathrm{L}$ of DMEM/F12) supplemented with Normacin (1\%, Invivogen, San Diego, CA, USA) was added to the wells beneath the inserts to keep the matrigel moist, and explants were allowed to adhere to the Matrigel overnight $\left(37^{\circ} \mathrm{C}, 3 \% \mathrm{O}_{2}\right.$, and $5 \%$ $\mathrm{CO}_{2}$ ) as described earlier [21]. The next day, $200 \mu \mathrm{L}$ of medium was added to the inserts and the explants were incubated (for $24 \mathrm{~h}$ ) to allow the formation of EVT outgrowths. Explant outgrowth was observed under a microscope. Only explants exhibiting EVT sprouting were included in the study. For $A B C G 2$ knockdown, explant media was supplemented with the siABCG2 transfection complexes or scrambled control (50 nmol/L-please see below). Explants were then photographed (at time zero: T0) using a Leica DFC400 camera (Leica Microsystems GmbH, Wetzlar, Germany) attached to a dissecting microscope. Photographs were taken after $24 \mathrm{~h}$ (T24) and $48 \mathrm{~h}$ (T48) post transfection. The area of outgrowth at T0, T24, and T48 was analyzed from the pictographs using image software and percent growth was calculated by dividing the difference between the final (T24 or T48) and initial (T0) area of outgrowth with the final area of outgrowth ${ }^{*} 100$. Each experiment was performed in triplicate with a total of $\mathrm{N}=3$ first trimester human placentae.

Explant tissues attached to Matrigel were collected by cutting the membrane from the transwell inserts, were washed once with PBS (1x), and were fixed with paraformaldehyde ( $4 \%, 1 \mathrm{~h})$. The tissues were dehydrated in ascending grades of ethanol, cleared in xylene, and embedded in paraffin. Sections $(5 \mu \mathrm{m})$ were mounted on slides for Immunohistochemistry.

\subsection{Immunohistochemistry}

Explants were processed for immunohistochemical analysis as previously described [10,22]. Briefly, slides were deparaffinized, rehydrated, and subjected to antigen retrieval with sodium citrate. After blocking with Dako protein block (Dako, Mississauga, ON, Canada), the slides were incubated overnight at $4{ }^{\circ} \mathrm{C}$ with primary antibodies: anti-mouse BCRP (1:200, BXP-21, ab3380, Millipore, Billerica, MA, USA), anti-mouse HLA-G (1:300, 4H84, Exbio, Burlington, ON, Canada), and anti-mouse CK7 (1:1000; M7018, Dako). In the controls, mouse or rabbit IgG1 (Dako) was added instead of the primary antibody. After incubation, the slides were washed and incubated with the corresponding biotinylated secondary antibody (1:300, $1 \mathrm{~h}$, Dako). Sections were washed in $1 \times$ PBS $(3 \times 10 \mathrm{~min})$ and incubated with streptavidin-HRP (30 min; Dako); immunostaining was detected with the peroxidase substrate kit DAB (Dako). The slides were counterstained with hematoxylin, dehydrated in ascending concentrations of ethanol, and cover slipped with mounting medium. Visualization was undertaken with an Olympus BX61 upright, motorized microscope, and representative images were captured using an Olympus DP72 digital camera (Olympus, Tokyo, Japan).

\subsection{Cell Line and Culture}

The first trimester human placental cell line HTR8/SVneo was kindly provided by Dr. Charles Graham, Queen's University. The cell line was developed using first trimester EVTs infected with simian virus 40 large T antigen (SV40) [23]. HTR-8/SVneo cell culture was performed as previously described [20]. Briefly, cells were cultured in Roswell Park Memorial Institute 1640 medium (RPMI; Thermo Fisher Scientific, Wilmington, NC, USA) supplemented with $10 \%$ fetal bovine serum (FBS; Wisent, St Bruno, QC, Canada), $100 \mathrm{IU} / \mathrm{mL}$ of penicillin, and $100 \mathrm{IU} / \mathrm{mL}$ of streptomycin at $20 \% \mathrm{O}_{2}$ $\left(5 \% \mathrm{CO}_{2}, 37^{\circ} \mathrm{C}\right)$ (Invitrogen Canada Inc., Burlington, ON, Canada). Cells were seeded (380,000 per 
well, respectively) in 6-well plates and cultured for $24 \mathrm{~h}$ at $20 \% \mathrm{O}_{2}\left(5 \% \mathrm{CO}_{2}, 37{ }^{\circ} \mathrm{C}\right)$ and were then treated with LPS (0.1 or $1 \mu \mathrm{g} / \mathrm{mL}$; Sigma-Aldrich, St. Louis, MO, USA) or ssRNA (1 or $2.5 \mu \mathrm{g} / \mathrm{mL}$; Invivogen, San Diego, CA, USA) for $12 \mathrm{~h}$ in dose ranges previously shown to elicit a trophoblast inflammatory response $[12,24,25]$. Cells and media were then collected and stored at $80^{\circ} \mathrm{C}$ for total RNA and protein extraction or enzyme-linked immunosorbent assay (ELISA).

\subsection{Quantitative Real Time PCR ( $q P C R$ )}

Total RNA was isolated from HTR-8/SVneo cell lines using RNeasy Plus Universal Mini Kit (Qiagen, Toronto, ON, Canada), as previously described $[12,13,26]$. RNA concentration and purity were assessed with a NanoDrop1000 Spectrophotometer (Thermo Scientific, Wilmington, NC, USA) and Experion RNA StdSens Analysis Kit (Bio-Rad, Mississauga, ON, Canada), respectively. RNA was reverse-transcribed into cDNA using the iScript Reverse Transcription Supermix (Bio-Rad). ABCG2, IL-6, IL-8, CCL2, TRL-4, and TRL-7 mRNA levels were measured by qPCR using SYBR Green reagent (Sigma-Aldrich) and the CFX 380 Real-Time system C1000 TM Thermal Cycler (Bio-Rad), with the following cycling conditions: initial denaturation at $95^{\circ} \mathrm{C}(2 \mathrm{~min})$ followed by 39 cycles of denaturation at $95^{\circ} \mathrm{C}(5 \mathrm{~s})$, and combined annealing and extension at $60^{\circ} \mathrm{C}(20 \mathrm{~s})$. Gene expression was normalized to the geometric mean of selected reference genes including TATA-binding protein (TBP) and hypoxanthine-guanine phosphoribosyltransferase (HPRT), which had stable expression after LPS or ssRNA treatments in the HTR-8/SVneo cell line. The relative expression of target genes was calculated by the $2^{-\Delta \Delta C T}$ method [27]. The primer sequences of all the assessed genes are shown in Table 1 [28].

Table 1. List of primers used in this study.

\begin{tabular}{|c|c|c|}
\hline Primer Name & Sequence & Reference \\
\hline \multirow[t]{2}{*}{$A B C G 2$} & Forward: 5'-TGGAATCCAGAACAGAGCTGGGGT-3' & Lye et al., 2018 \\
\hline & Reverse: 5'-AGAGTTCCACGGCTGAAACACTGC-3' & \\
\hline \multirow[t]{2}{*}{ IL-6 } & Forward: $5^{\prime}$-TGCAGAAAAAGGCAAAGAAT-3' & Potter et al., 2015 \\
\hline & Reverse: 5'-CTGACCAGAAGAAGGAATGC-3' & \\
\hline \multirow[t]{2}{*}{$I L-8$} & Forward: 5'-TGGGAACAAGAGGGCATCTG-3' & Lye et al., 2015 \\
\hline & Reverse: 5'-CCACCACTGCATCAAATTCATG-3' & \\
\hline \multirow[t]{2}{*}{ CCL2 } & Forward: 5'-TTCATTCCCCAAGGGCTCGCTCA-3' & Lye et al., 2015 \\
\hline & Reverse: 5'-AGCACAGATCTCCTTGGCCACAA-3' & \\
\hline \multirow[t]{2}{*}{$T L R-4$} & Forward: 5'-ATTTGTCTCCACAGCCACCA-3' & Lye et al., 2015 \\
\hline & Reverse: 5'-ACAGGAAACCCCATCCAGAG-3' & \\
\hline \multirow[t]{2}{*}{$H P R T$} & Forward: 5'-TGA CAC TGG CAA AAC AATGCA-3' & Drewlo et al., 2012 \\
\hline & Reverse: 5'-GGT CCT TTTCAC CAG CAA GCT-3' & \\
\hline \multirow[t]{2}{*}{ TBP } & Forward: 5'-TGC ACA GGA GCC AAG AGT GAA-3' & Drewlo et al., 2012 \\
\hline & Reverse: 5'-CAC ATC ACA GCT CCC CAC CA-3' & \\
\hline
\end{tabular}

\subsection{Immunoblotting}

Western blot analysis was conducted as previously described [11-13,22,26]. Briefly, protein isolated from cultured cells was extracted by sonication using lysis buffer $(1 \mathrm{~mol} / \mathrm{L}$ Tris-HCL pH 6.8, $2 \%$ SDS, $10 \%$ glycerol with added protease and phosphatase inhibitor cocktail; Thermo Scientific). The protein concentration was determined with the Pierce BCA Protein Assay kit (Thermo Scientific). Proteins were separated by electrophoresis $(30 \mu \mathrm{g} 100 \mathrm{~V}, 1 \mathrm{~h})$ using SDS polyacrylamide gels $(8 \%)$. Proteins were then transferred (10 $\mathrm{min}$ ) to polyvinylidene fluoride (PVDF) membrane using Trans-Blot Turbo (Bio-Rad). Membranes were blocked with skim milk ( $5 \% ; 1 \mathrm{~h}$ at room temperature). The primary antibodies used were anti-rabbit BCRP (dilution 1:3000; Abcam, ab63907, Toronto, ON, Canada) and anti-rabbit ERK2 (dilution 1:3000; Santa Cruz Biotechnology, Dallas, TX, USA). Blots were incubated with primary antibodies overnight at $4{ }^{\circ} \mathrm{C}$. The PVDF membranes were subsequently incubated for $1 \mathrm{~h}$ with HRP-linked anti-rabbit secondary antibody (GE Healthcare Bio-Science, Baie d'Urfe, QC, Canada) at concentrations of 1:10,000 (ERK2) and 1:15,000 (BCRP). Protein-antibody complexes were 
detected by incubating (for $5 \mathrm{~min}$ ) the PVDF membranes with Laminate Crescendo Western HRP Substrate (Millipore, Oak Drive, CA, USA) and chemiluminescence was detected under UV by using the ChemiDoc ${ }^{\mathrm{TM}}$ MP Imaging system (Bio-Rad). The protein band intensity was quantified using Image Lab ${ }^{\mathrm{TM}}$ software.

\subsection{Enzyme-Linked Immunosorbent Assay (ELISA)}

IL-6 and IL-8 concentrations in HTR-8/Vneo supernatant exposed to LPS, ssRNA, or VEH for $12 \mathrm{~h}$ were determined using a human IL-6/8 ELISA Development Kit (Invitrogen by Thermo Scientific, Wilmington, NC, USA) according to the manufacturer's instructions (minimum detection limit, $2 \mathrm{pg} / \mathrm{mL}$; intra-assay variation, $4.94 \%)$.

\subsection{Transient Transfection with siRNA Oligonucleotides}

Three different Stealth $A B C G 2$ siRNA duplexes, designed and synthesized by Shanghai GenePharma (Shanghai, China), were used for the transient inhibition of endogenous $A B C G 2$ in HTR8/SVneo cells. Sequences are provided in Table 2. HTR8/SVneo cells were seeded at a density of 13,000 cells/well in 96-well imagelock microplates (BioScience Inc., Ann Arbor, MI, USA). The following day, the cells were transfected using Lipofectamine RNAiMAX transfection reagent $(2 \mu \mathrm{L} / \mathrm{mL})$ according to the manufacturer's protocol. All ABCG2 siRNA duplexes were pooled in a cocktail $(50 \mathrm{nM})$ in equal proportions. An equivalent amount of scrambled siRNA was used as a control. The cells were harvested $24 \mathrm{~h}$ post transfection for RNA analysis and $48 \mathrm{~h}$ for protein or migration analysis.

Table 2. List of $A B C G 2-$ siRNAs used in this study.

\begin{tabular}{ccc}
\hline Number & & Sequence \\
\hline 1 & Antisense & AUAACCAGCUGAUUCAAAGUAUCCC \\
& Sense & GGGAUACUUUGAAUCAGC UGGUUAU \\
2 & Antisense & UAAUGAUGUCCAAGAAGAAGUCUGC \\
& Sense & CAGACUUCUUCUUGGACAUCAUUA \\
3 & Antisense & GGAGGCAAAUCUUCGUUAUTT \\
& Sense & AUAACGAAGAUUUGCCUCCTT \\
Negative Control & Antisense & GCGACGAUCUGCCUAAGAUdTdT \\
& Sense & AUCUUAGGCAGAUCGUCGCdTdT \\
\hline & Provided by Shanghai GenePharma, China.
\end{tabular}

\subsection{Cell Migration Assay}

To determine the effect of BCRP on HTR8/SVneo cell migration, 13,000 cells were seeded in 96-well imagelock plates. The next day, the cells were transfected with the $50 \mathrm{nM}$ pooled ABCG2-siRNAs (siABCG2-1 + siABCG2-2 + si $A B C G 2-3$ ) or scrambled control (NC) and were incubated for $48 \mathrm{~h}$ for effective knockdown on endogenous $A B C G 2$. Wounds were created across the diameter of each well using an automatic wound maker (Essen Biosciences, Ann Arbor, MI, USA) and the cells were washed twice $(1 \times$ PBS) to remove the floating cells. The cells were then replenished with the serum-reduced medium (Opti-MEM) and incubated in the IncuCyte ${ }^{\circledR}$ S3 system (Essen Bioscience, Ann Arbor, MI, USA), where all the wounds were imaged every $2 \mathrm{~h}$ for $36 \mathrm{~h}$. Cell migration was determined as the percent wound density by the IncuCyte ${ }^{\mathrm{TM}}$ software from the data collected every $2 \mathrm{~h}$ through the $36 \mathrm{~h}$. Percentage of Relative Wound Density (RWD) was determined by the Incucyte software while area under the curve (AUC) was calculated for each condition from mean RWD values to compare the treatments, as previously described [15].

The effect of pharmacological inhibition of BCRP on cell migration was assessed using the specific inhibitor Ko143 (Sigma-Aldrich). Cells were seeded at a density of 22,000 cells per well in imagelock plates and treated with Ko143 $(1 \mu \mathrm{M})$ or its diluent $(0.001 \%$ ethanol) as the vehicle for $2 \mathrm{~h}$ before they 
were wounded. The cells were wounded, washed, and imaged as described above. Ko143 $(1 \mu \mathrm{M})$ or its vehicle was maintained in the medium (serum reduced) during the migration assay.

The effect of the infection challenges on HTR8/SVneo cell migration was assessed by seeding 22,000 cells per well in 96-well imagelock culture plates (Essen Biosciences, Ann Arbor, MI, USA). The following day, the cells were treated with LPS $(0.1$ or $1 \mu \mathrm{g} / \mathrm{mL})$ or its vehicle (water) for $24 \mathrm{~h}$. Similarly, cells were pre-treated with ssRNA ( 1 or $2.5 \mu \mathrm{g} / \mathrm{mL}$ ) or its vehicle (water) for $24 \mathrm{~h}$. The treatments were replenished after the wounded cells were washed and then they were imaged and analyzed by the IncuCyte ${ }^{\circledR}$ S3 system over the next $36 \mathrm{~h}$.

\subsection{Cell Proliferation Assay}

To verify if the effect of BCRP on cell migration is due to altered cell migration and not due to a secondary effect on cell proliferation, we replicated the conditions of the migration assay in regular 96-well culture plates and subjected them to cell proliferation assessment using the incuCyte system. Briefly, 5000 cells were seeded in 96-well culture plates. The next day, cells were transfected with the $50 \mathrm{nM}$ pooled $A B C G 2$-siRNAs, as described in the previous section, for $24 \mathrm{~h}$ and were then incubated in the IncuCyte ${ }^{\circledR}$ S3 system (Essen Bioscience, Ann Arbor, MI, USA) in serum-reduced medium (Opti-Mem, similar to the migration assay), where cells were imaged every $2 \mathrm{~h}$ for the next $60 \mathrm{~h}$. Cell proliferation was determined as the percent confluence by the IncuCyte ${ }^{\mathrm{TM}}$ software from the data gained every $2 \mathrm{~h}$ through the $60 \mathrm{~h}$. Area under the curve (AUC) was calculated for each condition from mean \% confluence values to compare the treatments as described previously [15]. The validity of the effect of pharmacological inhibition of BCRP and the effect of bacterial and viral infective challenges on cell migration (and not on cell proliferation) was similarly assessed, using approaches described above.

To determine the effect of BCRP on cell proliferation under the regular growth conditions, we transfected/treated the HTR8/SVneo cells as described in the previous section for $24 \mathrm{~h}$ and then incubated the cells in complete medium (with 10\% FBS) and assessed cell proliferation through the incuCyte system as described above.

\subsection{Statistical Analysis}

All analyses were conducted blind to the experimental conditions. Data analyses were performed with Prism version 6 (GraphPad Software Inc., San Diego, CA, USA) and data were assessed for normal distribution using D'Agostino and Pearson or the Shiparo-Wilk test. Differences in migration and proliferation following the pharmacological and molecular inhibition of BCRP expression were assessed by unpaired $t$-test. Differences between the treatments were determined by one-way ANOVA followed by the Newman-Keuls post-hoc test.

\section{Results}

\subsection{Expression of BCRP Is Enriched in Column Cytotrophoblasts (CCT) and Extravillous Trophoblasts (EVTs)} in Placental Explants

Previously, we reported that BCRP is primarily localized to ST in the apical membrane of first trimester floating villi (lacking EVT columns) [10,22]. In this study, we examined BCRP immunolocalization in EVT explant cultures enriched in matrigel where sprouting and migration/invasion of EVTs from the tips of CCTs is identifiable. Immunohistochemistry revealed BCRP immunostaining in ST, CT, CCT, as well as, EVTs invading into the matrigel and at the tips of CCT (Figure 1E,F). Specific trophoblast lineages were histologically identified by comparing BCRP signals in paired serial tissue sections stained with cytokeratin 7 to identify CT, CCT, and ST (Figure 1A,B), and with HLA-G to identify EVTs (Figure 1C,D). Respective IgG controls showed no immunostaining (Figure 1G,H). 


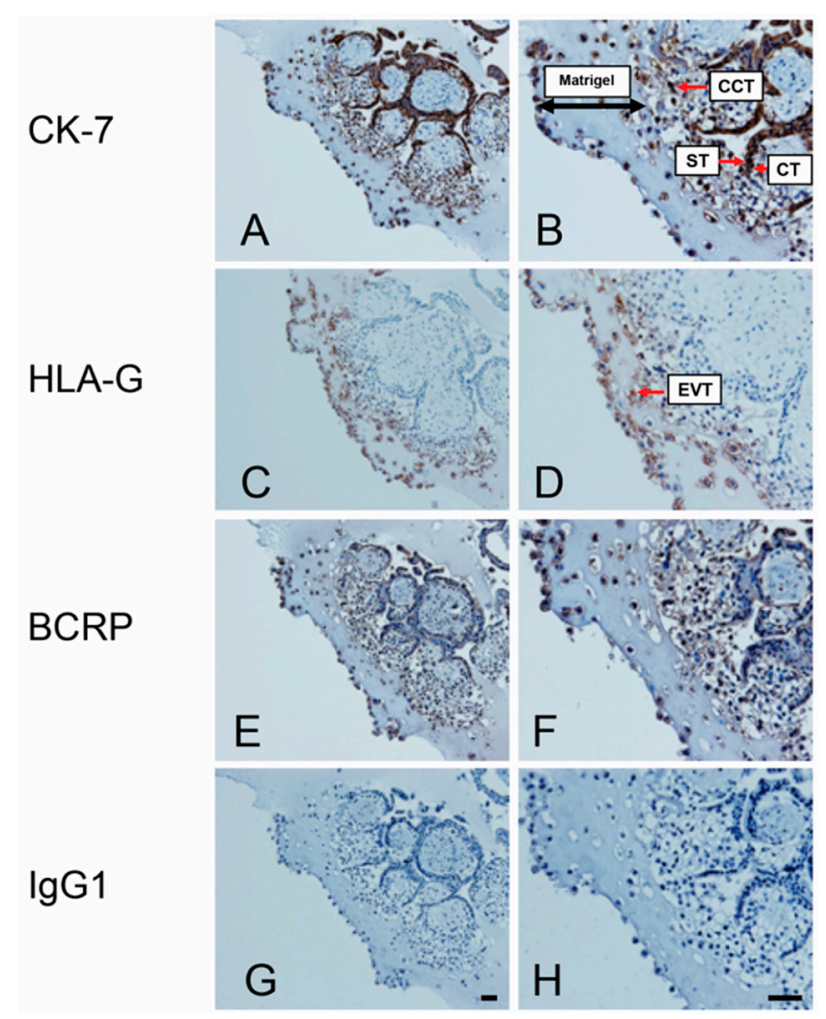

Figure 1. Breast cancer resistance protein (BCRP) is expressed in diverse trophoblast lineages including extravillous trophoblasts (EVT). Representative immunohistochemistry (IHC) images from tissue sections of first trimester human placental explants cultured on Matrigel $(n=6)$, showing: (A,B) cytokeratin 7 (CK7) expression (a trophoblast marker) in cytotrophoblast (CT), column cytotrophoblast (CCT), syncytiotrophoblast (ST), and extravillous trophoblast (EVT); (C,D) HLA-G expression in EVTs (EVT cell marker); (E,F) BCRP protein localization to CT, CCT, ST, and EVT; $(\mathbf{G}, \mathbf{H})$ non-immune mouse IgG1 control. Scalebars $=50 \mu \mathrm{m}$.

\subsection{ABCG2 Knockdown or Functional Inhibition of BCRP Stimulates EVT Cell Migration (HTR8/SVneo Cells)}

First, we validated the ability of the si $A B C G 2$ to reduce the mRNA and protein expression of $A B C G 2$ and BCRP in HTR8/SVneo cells, which are capable of migration in vitro. Significant down-regulation of BCRP (62.37\%, Figure 2F) and ABCG2 (63.85\%, Figure 2B) was observed following $48 \mathrm{~h}$ of si $A B C G 2$ duplex treatment. Next, we determined the specificity of siRNA against $A B C G 2$ by examining the mRNA levels of other related $A B C$ transporters that are known to be expressed in trophoblasts: $A B C B 1$, $A B C C 2$, and $A B C C 3$ [29]. The siRNA sequences were with unique specificity against $A B C G 2$ mRNA. Sequence alignment with other $A B C$ transporters is shown in Figure 2A. We did not find off-target effects of si $A B C G 2$ at the dose and duration of our experiments (Figure $2 \mathrm{C}-\mathrm{E}$ ). Similarly, we did not find differences in protein expression of another trophoblast-enriched ABC transporter, ABCA6 [29] (Figure $2 \mathrm{G}$ ), confirming the specificity of the siABCG2 procedure. HTR8/SVneo cells were transiently transfected with si $A B C G 2$ oligos $(50 \mathrm{nM})$ for $48 \mathrm{~h}$ (the time point where we observed significant reduction of BCRP protein levels compared to scrambled siRNA control) and were then subjected to wound-scratch assay and IncuCyte ${ }^{\mathrm{TM}}$-facilitated imaging and analyses. We found a significant $(p<0.001)$ increase in HTR8/SVneo cell migration in siABCG2 transfected cells compared to the scrambled control (Figure $3 \mathrm{~A}-\mathrm{C}$ ), with no changes in cell proliferation under similar culture conditions (Figure 3D,E and Supplementary Figure S2), strongly suggesting that BCRP inhibits EVT migration. The inhibition of BCRP function using a BCRP specific inhibitor, Ko143, resulted in a similar significant increase $(p<0.05)$ in trophoblast migration (Figure 3F-H) and did not alter HTR8/SVneo proliferation (Figure $3 \mathrm{I}, \mathrm{J})$, confirming that BCRP inhibits EVT migration. 
A

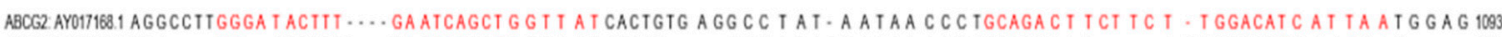

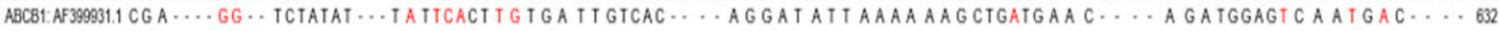

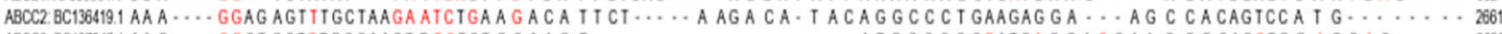

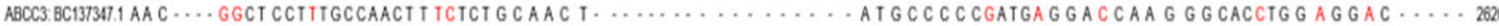

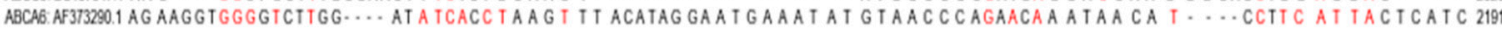

B

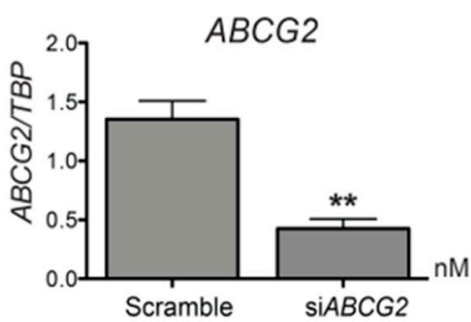

D

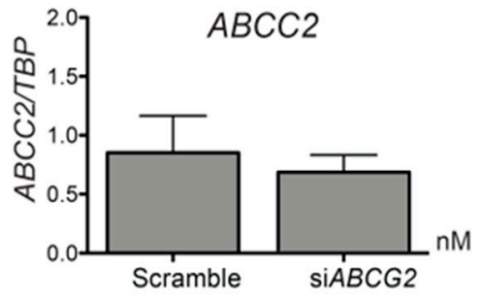

F

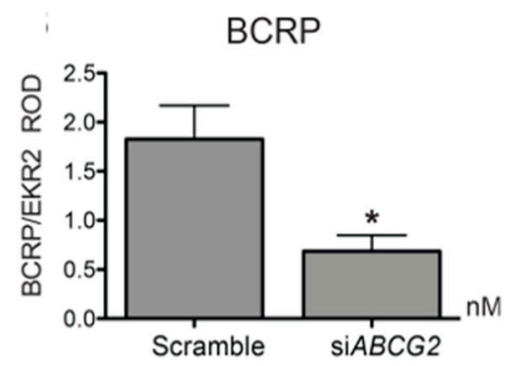

BCRP

ERK2

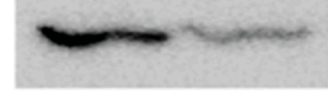

$72 \mathrm{kDa}$

$38 \mathrm{kDa}$
C

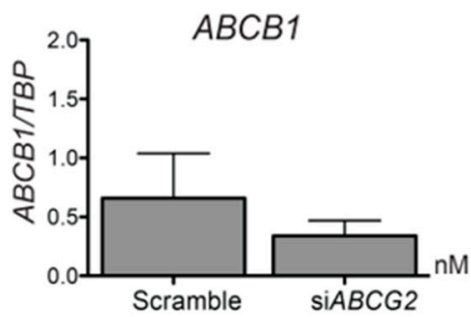

E

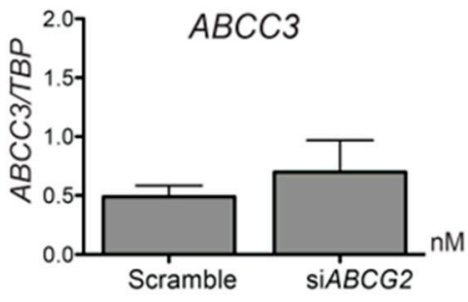

G

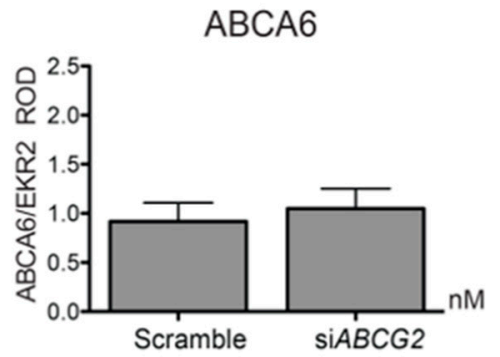

ABCA6

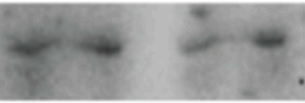

$180 \mathrm{kDa}$

ERK2

Figure 2. Validation of siRNA mediated knock down of BCRP in HTR8/Svneo cell line. (A) Target region of $A B C G 2$ siRNA sequences ( 1 \& 2 shown in red) aligned with the mRNA of $A B C G 2, A B C B 1, A B C C 2$, $A B C C 3$ and $A B C A 6$ using Multiple Sequence Analysis by Clustal Omega (EMBL-EBI). (B-E) mRNA analysis post siRNA transfection. TBP was used as reference gene for data normalization. $A B C G 2 \mathrm{mRNA}$ was significantly downregulated while that of the other transporter genes; $A B C B 1, A B C C 2$ and $A B C C 3$ remained unaffected in siRNA transfected cells compared to the scrambled control ones. $(\mathbf{F}-\mathbf{G})$ Western blot analysis of cells post siRNA transfection. BCRP protein was downregulated $48 \mathrm{~h}$ post siABCG2 transfection while ABCA6 protein remain unaffected illustrating the specificity of siRNA for BCRP. Graphs show densitometric analysis of BCRP expression (F), and ABCA6 (G) normalized to total ERK2. Statistical differences were tested by unpaired $\mathrm{t}$ test, ${ }^{*} p<0.05$, ${ }^{* *} p<0.01$ mRNA $\mathrm{n}=4$; Protein $\mathrm{n}=3$ per group. 


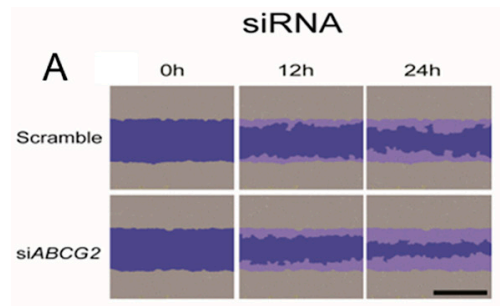

B
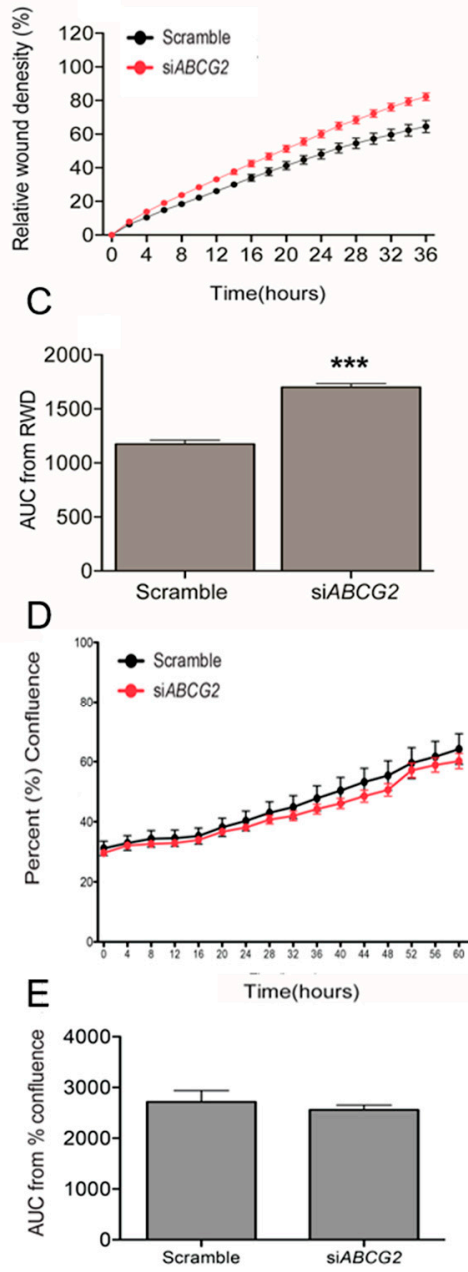

Ko143

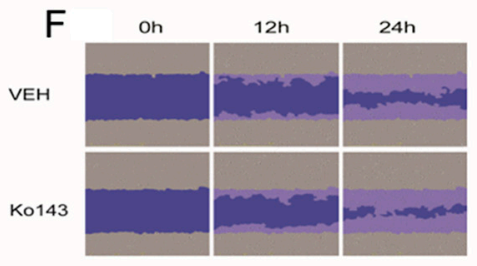

G
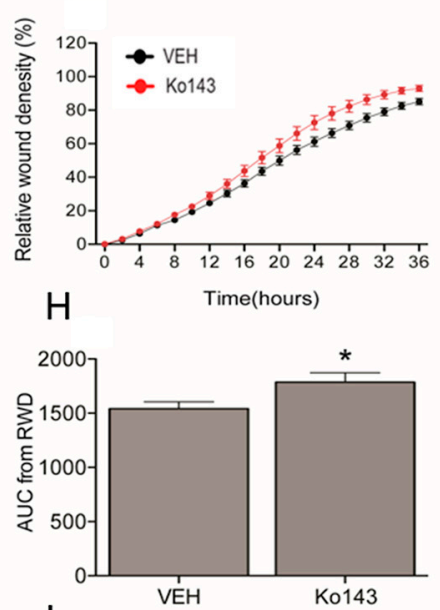

I

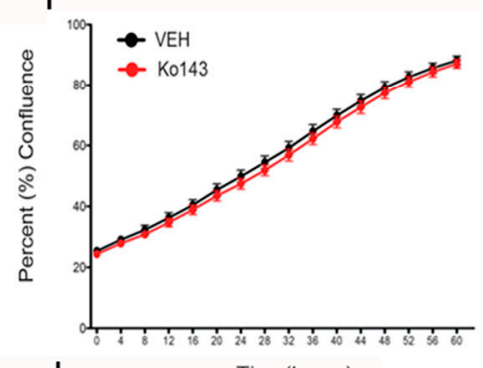

J

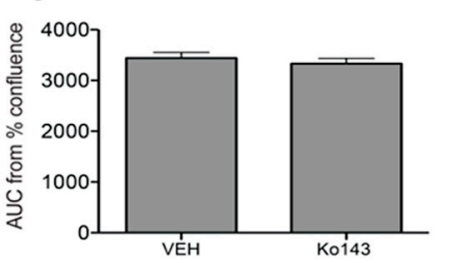

Figure 3. Inhibition of BCRP using siRNA or BCRP specific inhibitor Ko143 increases migration of human EVTs without affecting cell proliferation. HTR8/Svneo cells were cultured in a monolayer in 96-well plates and a wound was made across the diameter of wells using a 96 well Wound Maker. (A-C) Cells were transfected with $50 \mathrm{nM} \mathrm{siABCG2}$ or its scrambled sequence for $48 \mathrm{~h}$ prior to wounding and then imaged every $2 \mathrm{~h}$ for $36 \mathrm{~h}$ to determine relative wound density. (F-H) Cells were washed, pre-treated with Ko143 or its vehicle (VEH) for $2 \mathrm{~h}$ and imaged with IncuCyte ${ }^{\mathrm{TM}}$ every $2 \mathrm{~h}$ for $36 \mathrm{~h}$ to determine relative wound density. $(\mathbf{B}, \mathrm{G})$ Quantification of relative wound density over the period of $36 \mathrm{~h}$. $(\mathbf{C}, \mathbf{H})$ Comparison between treatments is shown by Area under curve analysis of the replicates. Data are expressed as means $\pm S E M, n=6$ per group. Statistical differences were tested by unpaired $t$ test. ${ }^{*} p<0.05$ versus VEH, ${ }^{* * *} p<0.001$ versus VEH. Scale bars $=600 \mu \mathrm{m}$. (D,E,I,J) cells were transfected with $50 \mathrm{nM}$ of siABCG2 or scramble control for $24 \mathrm{~h}$ and time lapse imaging was performed by IncuCyte ${ }^{\mathrm{TM}}$ every $4 \mathrm{~h}$ for $60 \mathrm{~h}$. (D,I) Percent confluence was quantified by incuCyte software and the graph shows mean of $n=6$. (E,J) Comparison between treatments is shown by Area under curve analysis of replicates. Statistical differences were tested by unpaired t-test. No differences were found between the treatments versus the vehicle control. 
3.3. Bacterial and Viral Infection Mimics Activate a Pro-Inflammatory Response in EVTs and Impair ABCG2 and BCRP Expression (HTR8/SVneo Cells)

LPS treatment $(1 \mu \mathrm{g} / \mathrm{mL} ; 12 \mathrm{~h})$ of HTR8/SVneo cells significantly $(p<0.01)$ decreased ABCG2 mRNA expression (Figure 4A), while ssRNA exposure repressed ABCG2 mRNA at both the low and high doses $(1 \mu \mathrm{g} / \mathrm{mL}: p<0.05,2.5 \mu \mathrm{g} / \mathrm{mL}: p<0.05$, Figure $4 \mathrm{~B})$, respectively. Since cytokine and chemokine release is the primary systemic response after bacterial or viral infection, we evaluated the LPS and ssRNA inflammatory responses by examining the induction of IL-6, IL-8, and CCL2. Both LPS treatments increased the levels of expression of Interleukin (IL)-6 mRNA (Figure 4C), IL-8 (Figure 4E), and C-C Motif Chemokine Ligand 2 (CCL2; Figure 4G) mRNA. High dose ssRNA treatment increased levels of IL-6 (Figure 4D) and IL-8 mRNA (Figure 4F) at the high dose whereas CCL2 mRNA expression (Figure $4 \mathrm{H}$ ) remained unchanged after treatment. Similar to mRNA expression, we found a significant decrease in BCRP protein following $12 \mathrm{~h}$ exposure to low and high doses of LPS and ssRNA (Figure 5A,B). There was also a significant increase in IL-8 levels in the culture media after $12 \mathrm{~h}$ exposure to low dose LPS $(p<0.01)$ and high dose ssRNA $(p<0.001)$, but no change in IL-6 levels (Figure 5C-F).

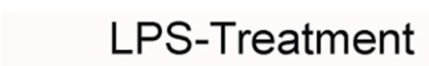

A
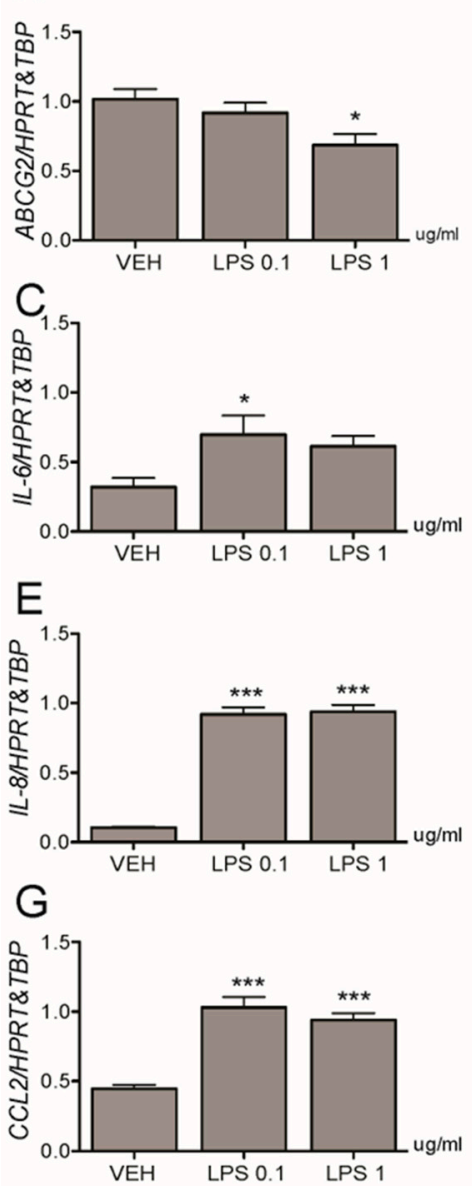

ssRNA-Treatment

B
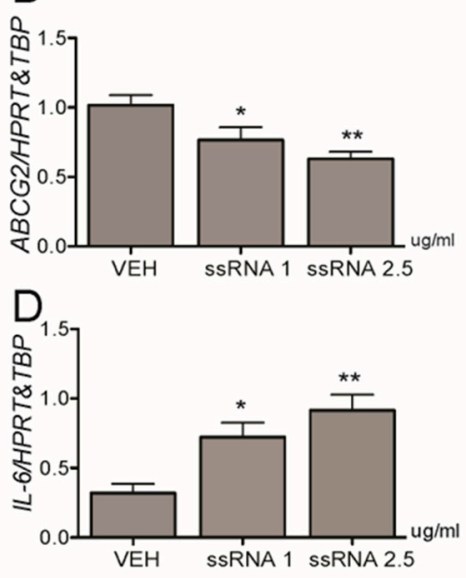

$\mathrm{F}$

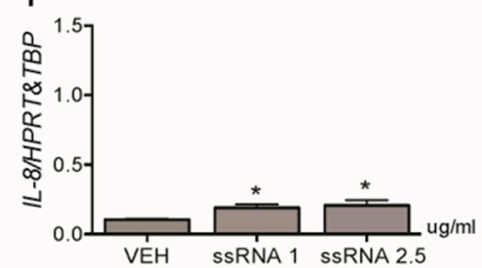

$\mathrm{H}$

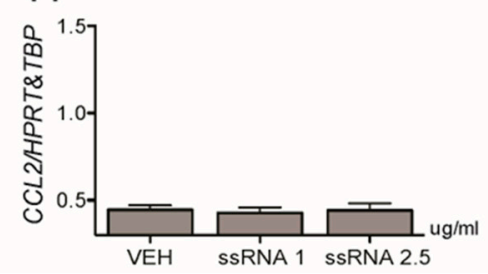

ABCG2

IL-6

IL-8

CCL2

Figure 4. Effects of lipopolysaccharide (LPS, left panel) and single stranded RNA (ssRNA, right panel) on ABCG2 (A,B), IL-6 (C,D), IL-8 (E,F), and CCL2 (G,H) expression in human HTR8/SVneo cells. Cells were treated with LPS $(0.1$ or $1 \mu \mathrm{g} / \mathrm{mL})$ or ssRNA $(1$ or $2.5 \mu \mathrm{g} / \mathrm{mL})$ or their vehicle control (VEH) for $12 \mathrm{~h}$. mRNA expression was assessed by qPCR and the geometric mean of the two reference genes: HPRT and TBP were used for normalization. Data are expressed as means $\pm \mathrm{SEM}, \mathrm{n}=6$ per group. Statistical differences were tested by one-way ANOVA followed by the Newman-Keuls post-hoc test. ${ }^{*} p<0.05,{ }^{* *} p<0.01$, and ${ }^{* * *} p<0.001$ versus VEH. 

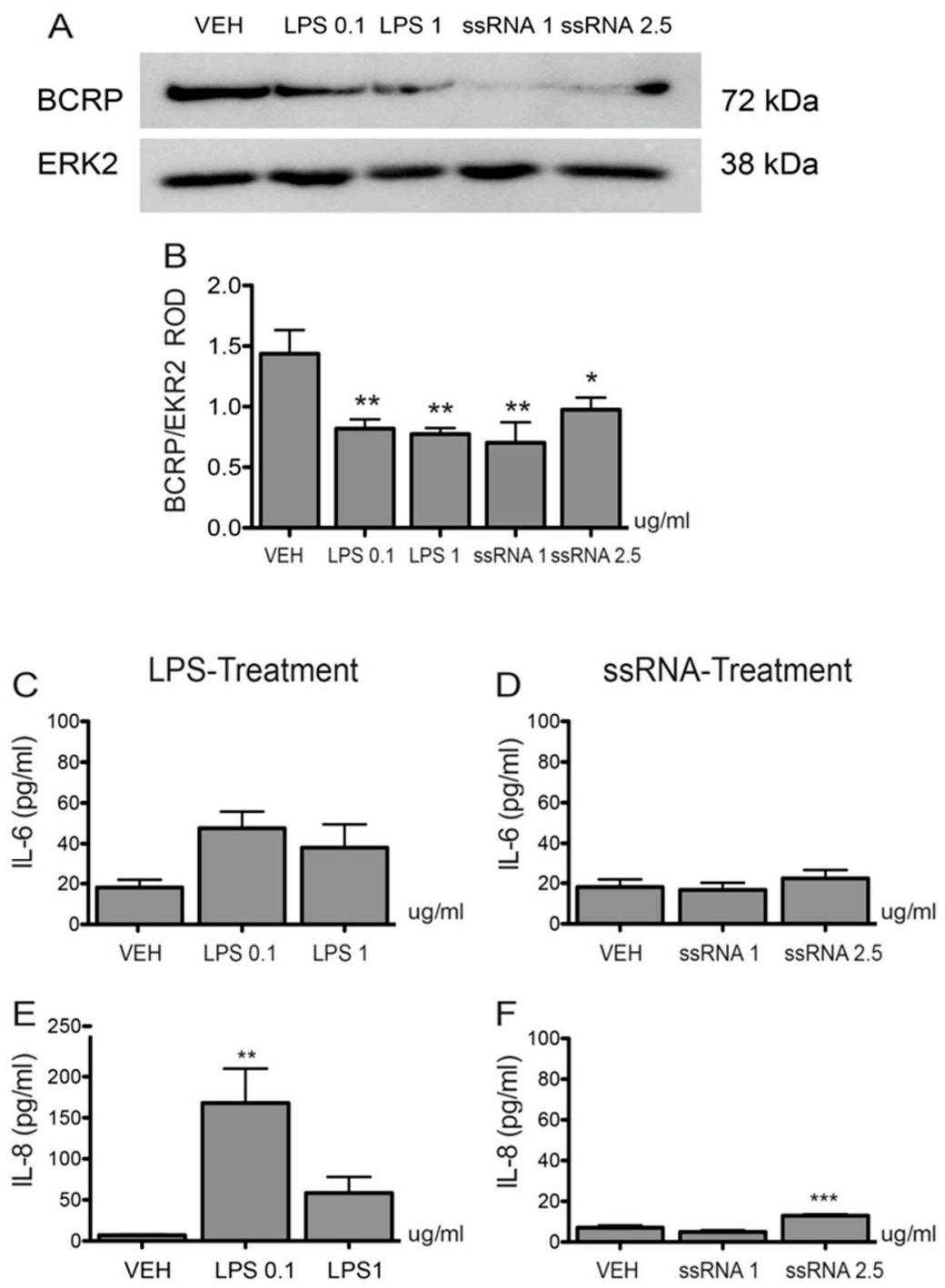

Figure 5. Effect of LPS and ssRNA on BCRP protein expression and IL-6 and IL-8 secretion in HTR8/Svneo cells. Cells were treated with LPS $(0.1$ or $1 \mu \mathrm{g} / \mathrm{mL})$ or ssRNA $(1$ or $2.5 \mu \mathrm{g} / \mathrm{mL})$ or their vehicle control (VEH) for $12 \mathrm{~h}$. (A) Representative western blot for BCRP expression. (B) Densitometric analysis of BCRP expression normalized to ERK2. Secreted IL-6 (C,D) and IL-8 (E,F) protein levels were measured from HTR8/SVneo cell culture supernatants by enzyme-linked immunosorbent assay (ELISA) $12 \mathrm{~h}$ post treatment with $1 \mu \mathrm{g} / \mathrm{mL}$ LPS (C,E) or $2.5 \mu \mathrm{g} / \mathrm{mL}$ ssRNA (D,F) or with VEH. Data are expressed as means \pm SEM, $\mathrm{n}=6$ experiments. Statistical differences were tested by one-way ANOVA followed by the Newman-Keuls post-hoc test. ${ }^{*} p<0.05,{ }^{* *} p<0.01,{ }^{* * *} p<0.001$ versus VEH.

\subsection{LPS and ssRNA Exposure Increases EVT Migration (HTR8/SVneo Cells)}

Since LPS and ssRNA decreased BCRP expression in EVT-like cells, we undertook a series of experiments to determine if LPS and ssRNA treatments affect EVT migration. The wound-scratch assay revealed that cells exposed to low or high doses of LPS (Figure 6A-C) and ssRNA (Figure 6E-G) exhibited a significantly higher \% wound density than cells treated with the vehicle. Analysis of data by the area under the curve (AUC) showed significant $(p<0.01)$ increases in the migration of cells exposed to LPS (Figure 6C) or ssRNA (Figure 6G), with no changes in cell proliferation (Figure 6D,H and Supplementary Figure S2). 

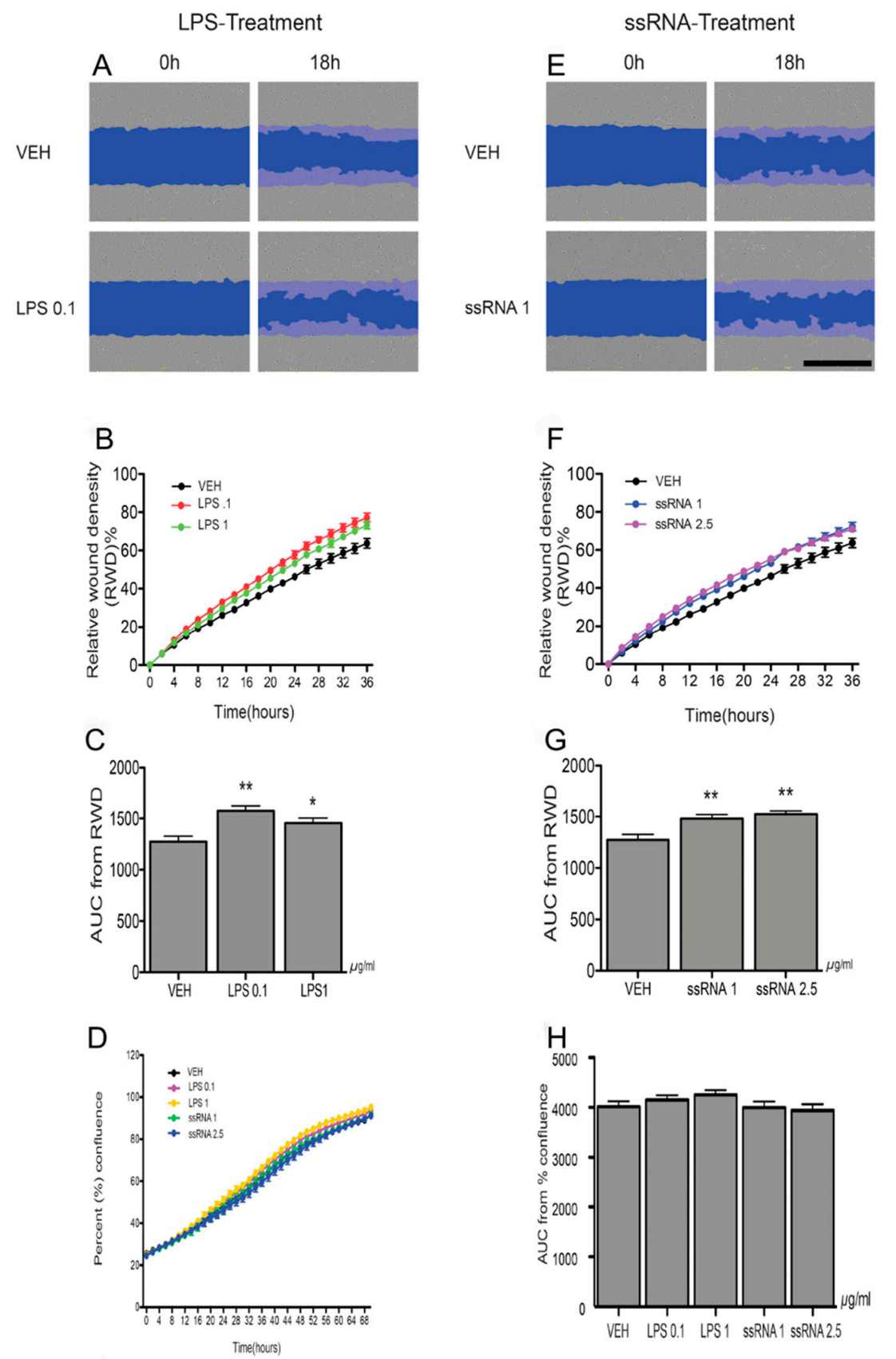

Figure 6. LPS and ssRNA induce human EVT cell migration. HTR8/Svneo cells were cultured in 96-well plates. A wound was made on the cell monolayer using 96-well Wound Maker and cells were imaged with IncuCyte ${ }^{\mathrm{TM}}$ ) every $2 \mathrm{~h}$ for $36 \mathrm{~h}$ post treatment (see Materials and Methods). (A,E) Representative images of human EVT migration at $0 \mathrm{~h}$ and $16 \mathrm{~h}$. The wound area is artificially coloured blue to highlight the migration of cells into the wound. (B,F) Graphs show the relative wound density (\%) in cells treated with LPS ( 0.1 or $1 \mu \mathrm{g} / \mathrm{mL}$ ) or ssRNA (1 or $2.5 \mu \mathrm{g} / \mathrm{mL}$ ) or their vehicle control (VEH) for $24 \mathrm{~h}$. $(\mathrm{C}, \mathrm{G})$ Histograms show comparison between treatments depicted by Area under the curve analysis of the replicates. (D,H) LPS and ssRNA treatment did not affect EVT cell proliferation. Cells were treated with LPS ( 0.1 or $1 \mu \mathrm{g} / \mathrm{mL}$ ) or ssRNA (1 or $2.5 \mu \mathrm{g} / \mathrm{mL}$ ) or their vehicle control (VEH), and time lapse imaging was performed by IncuCyteTM every $2 \mathrm{~h}$ for $72 \mathrm{~h}$. (D) Percent confluence was quantified by incuCyte software. (H) Comparison between treatments is shown by Area under the curve analysis of the replicates. Data are expressed as means $\pm S E M, n=6$ per treatment group. Statistical differences were tested by one-way ANOVA followed by the Newman-Keuls post-hoc test. ${ }^{*} p<0.05,{ }^{* *} p<0.01$ versus VEH. Scale bars $=600 \mu \mathrm{m}$. 


\subsection{ABCG2 Knockdown Stimulates EVT Cell Migration in Placental Explants}

We used human placental explants as an ex-vivo model of human placenta to determine the physiological significance of BCRP on EVT function and placentation. Following the transfer of first trimester human placental explants to Matrigel coated transwell inserts, villi with visible signs of EVT outgrowths were treated with siABCG2 or control oligos and were assessed the time of transfection (T0), at $24 \mathrm{~h}$ (T24), and $48 \mathrm{~h}$ (T48) post-transfection. EVT migration was determined by comparing the percent EVT outgrowth in the control versus $\triangle i A B C G 2$ treated explants. There was a substantial reduction of BCRP expression in the placental villi of siABCG2 treated explants compared to the controls, as determined by immunohistochemistry (Figure 7). Silencing of $A B C G 2$ resulted in significantly greater expansion (migration and invasion) of the EVT outgrowth on the Matrigel at $24 \mathrm{~h}$ $(p<0.001)$ and $48 \mathrm{~h}(p<0.05)$ compared to the control (Figure 7A,B). HLA-G was used as a marker of EVT to verify the migration and invasion of EVTs across the Matrigel in siABCG2 versus control explants, and CK7 was used as a trophoblast marker (Figure 7C).
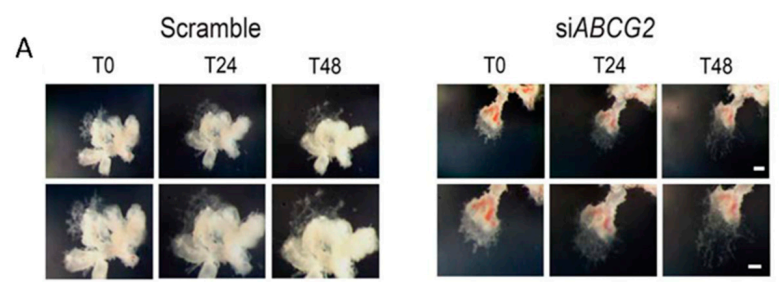

B

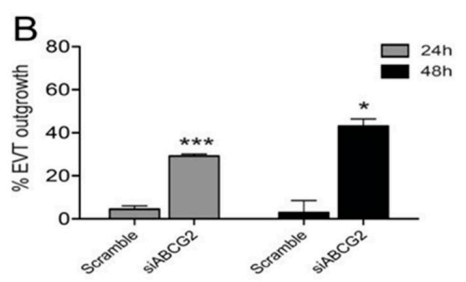

C

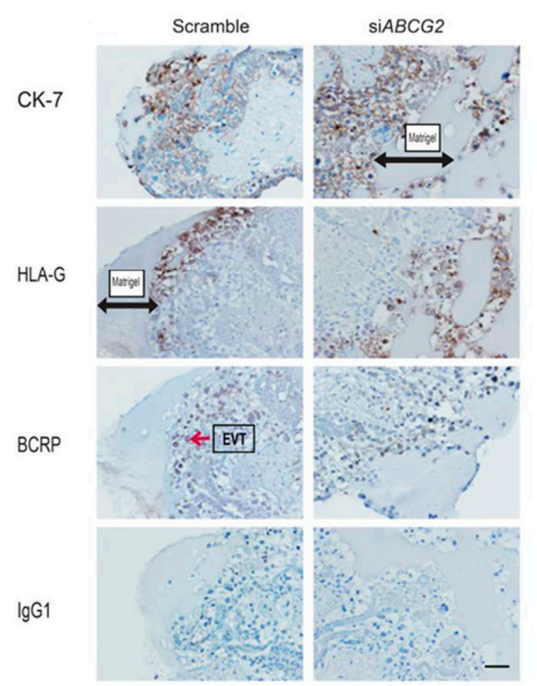

Figure 7. ABCG2 knockdown stimulated EVT cell migration in human placental explants. (A) Representative images of 7-week placental explants treated with Scrambled (control) siRNA or siABCG2 at T0, T24, and T48. (B) Graph shows mean \pm SEM ( $\mathrm{n}=3$ women). Statistical significance between scramble control and siABCG2 was determined by paired $t$-test, ${ }^{*} p<0.05$ and ${ }^{* * *} p<0.001$. Scale bar $=200 \mu \mathrm{m}$. (C) Representative immunohistochemistry images from tissue sections of first trimester human placental explants cultured on Matrigel and treated with $50 \mathrm{nM}$ of control siRNA or siABCG2 for $48 \mathrm{~h}(\mathrm{n}=3)$, showing downregulation of BCRP in the siABCG2 tissue versus the control. Cytokeratin (CK-7) staining is shown as a marker of trophoblasts (including CCT, CT, STB, and EVT), and HLA-G as a marker of EVTs. Scale bars $=50 \mu \mathrm{m}$. 


\section{Discussion}

Our study provides new insights into the regulation of EVT migration during early placental development. We report, for the first time, that BCRP, which is well known for its role as an efflux transporter, inhibits EVT cell migration in HTR8/SVneo (EVT-like) cells and in first trimester derived EVTs. In addition to being present in STs, BCRP is also expressed in CCTs and EVTs in human placenta during the first trimester, implicating that it has a role in EVT function. Inhibition of BCRP with siABCG2 or Ko143 increased cell migration in the HTR8/SVneo (EVT-like) cell line over $36 \mathrm{~h}$, without affecting proliferation. We also demonstrated that LPS and ssRNA exposure decreased $A B C G 2$ and BCRP expression in EVTs and stimulated EVT migration. Together, these data suggest that BCRP functions as an inhibitor of EVT migration and that infection may lead to increased EVT migration.

In the present study, we effectively knocked down BCRP expression using siRNA duplex technology, which resulted in increased migration of EVT cells, with no alteration in the proliferation index. It is important to note that we used a novel automated approach to monitor and analyze the migration of EVT cells. We calculated the \% wound density and the area under the curve generated from the data recorded every $2 \mathrm{~h}$ over $36 \mathrm{~h}$ using IncuCyte ${ }^{\mathrm{TM}}$ technology [15]. Pharmacological inhibition of $\mathrm{BCRP}$ resulted in a similar outcome. Interestingly, this contrasts with reports from cancer cell lines, which suggest that BCRP increases the migration of glioma and pancreatic cancer cells $[16,17,30]$ and inhibits the proliferation in other epithelial-like cancer cell lines [14]. These differences may result from the fact that the cancer cell lines are derived from human tumors, whereas HTR8/SVneo cells are derived from physiological EVTs [23], thus illustrating different actions of BCRP modulating cell migration in physiological and in neoplastic phenotypes. Further, diverse cancer cells may commonly exhibit increased basal expression of $A B C G 2$ and BCRP, an important mechanism conferring multidrug resistance to chemotherapeutic drugs [31]. This is postulated to be an adaptation to the rearrangement of intracellular signaling pathways undertaken by malignant cells to promote invasiveness [32].

In a previous study, we reported that P-glycoprotein (P-gp), another ABC transporter related to ST-mediated fetal protection, reduces HTR8/SVneo cell proliferation and invasion [20]. While the contrasting actions of BCRP and P-gp in early placentation require further investigation, it is attractive to speculate that P-gp drives placentation by enhancing EVT migration/invasion, while BCRP likely controls the extent of EVT penetration within the decidua. The mechanisms by which BCRP modulates EVT migration remains to be determined. BCRP may regulate the transport and activity of substrates which are critical to cell migration (such as extracellular matrix (ECM) adhesion molecules). P-gp and BCRP are known to interact with CD44 to modulate cancer cell migration/invasion [33,34]. It is also possible that P-gp and BCRP have shared mediators controlling EVT cell migration. For example, CD44 and hyaluronic acid (HA) mediate cell-cell/cell-matrix adhesion and, hence, affect cell migration [35-37], and it is documented that CD44/HA on the cell surface of EVTs are important mediators of EVT invasion [38]. The STRING database of protein-protein interaction indicates interaction between CD44 and BCRP (https://string-db.org/cgi/network.pl?taskId=okGQMLIRXDFw). Based on this, it is possible to speculate that BCRP competes with P-gp for CD44 binding, interferes with the CD44/HA mediated adhesion properties of EVTs, and, hence, impedes EVT migration/invasion. This possibility requires further investigation.

In the present study, LPS treatment, which models bacterial infection via TLR-4 activation [39], decreased ABCG2 mRNA and BCRP protein expression in HTR-8/SVneo cells. This indicates that bacterial infection in early human pregnancy has the potential to affect EVT migration through the modulation of BCRP expression. This pattern of BCRP inhibition is consistent with our previous report showing that $A B C G 2$ and BCRP expression was decreased $24 \mathrm{~h}$ after exposure of first trimester human explants to LPS [12]. In the rat, previous studies have shown LPS to down-regulate placental Abcg2 mRNA [40]. No studies have investigated the effect of LPS on BCRP activity, however in mid-gestation, LPS inhibited the P-gp (encoded by $A b c b 1 a$ and $A b c b 1 b$ in rodents) efflux transporter in the mouse placenta [41]. Together, these studies suggest that the regulation of placental ABCG2 by LPS is gestational age-dependent. Importantly, it also indicates that bacterial infection has the potential to 
compromise normal EVT migration and fetal protection by inhibiting BCRP expression in EVTs and in the ST, respectively.

Exposure to ssRNA, which models viral infections and induces trophoblast pro-inflammatory responses via the activation of TLR8 and non-TLR8 signaling pathways [25], also decreased ABCG2 mRNA and BCRP protein expression in EVTs. This indicates that viral infection may, via decreased expression of BCRP, disrupt normal EVT migration. There are no previous reports of ssRNA modulating placental BCRP expression, though Poly (I:C), a synthetic analog of double stranded RNA (dsRNA) that acts via TLR-3 activation [42], has been shown to decrease ABCG2 in third trimester human placental explants [12] and in the late gestation rat placenta [40]. No studies have assessed the effect of Poly (I:C) on BCRP function. However, Poly (I:C) inhibited P-gp activity in the fetal mouse blood-brain barrier, but did not alter placental P-gp function [43], suggesting that the effects of dsRNA viral infection on P-gp mediated fetal protection are tissue barrier dependent. Future studies investigating the role of ssRNA regulating P-gp and BCRP function in developing barriers are warranted.

Maternal infection with single-stranded RNA viruses capable of crossing the placental barrier, i.e., zika (ZIKV) and rubella viruses [44,45], elicit severe obstetric outcomes including microencephaly, cerebral palsy, intellectual disability, and other sequelae $[46,47]$. In the present study, we showed that infection with ssRNA (which also include influenza (flu virus), rhinovirus (common cold virus), retrovirus (HIV and HTLV1), and coronavirus (upper-respiratory illnesses virus)) (Potter et al. 2015; Luo et al. 2018) in early-pregnancy has the potential to disrupt normal EVT migration and ultimately placentation, placental function, and fetal development. In this context, human placentae infected by ZIKV exhibit marked villous immaturity and increased the ratio of syncytial sprouts (syncytial nuclei aggregation at the outer trophoblastic wall) $[48,49]$. This provides pathological evidence of uteroplacental malperfusion, typically associated with deranged EVT migration into the decidualized endometrium, resulting in poor myometrial spiral arteries remodeling and reperfusion [50]. Further, viral, bacterial, and parasitic infections have been related to the enhancement of the likelihood of PE, through the modulation of pro-inflammatory cytokines, oxidative stress, and anti-angiogenic proteins at the early maternal fetal interface [51].

We have shown that ssRNA increased HTR-8/SVneo migration. Importantly, no previous studies have investigated the impact of ssRNA on trophoblast (EVT) migration or the migration of other normal somatic cells. However, studies on cancer cells have shown that ssRNA does not affect the migration and invasion of melanoma cells (Liu et al., 2018).

In the present study, we provide evidence that ABCG2 and BCRP inhibit EVT migration and are repressed by bacterial and viral infective challenges. Our results suggest that the downregulation of BCRP may be involved in the cellular pathways by which infection increases EVT cell migration. However, we cannot rule out that other ABC transporters, modulated by LPS and ssRNA in our EVT culture systems, may have contributed to the increased migration rates herein observed, following infective challenges. Further, ABCG2 and BCRP are highly responsive to a number of cytokines [9] and, in the present study, we have shown that LPS and ssRNA increased IL-6 (mRNA level only) and IL-8 secretion (mRNA and protein), suggesting that these cytokines inhibit or have additional inhibitory effects on $A B C G 2$ and BCRP expression in EVTs, a hypothesis that requires further investigation.

In conclusion, we have identified a novel role for BCRP in early placentation (Figure 8). The present study has demonstrated that EVTs express $A B C G 2$ and BCRP and that BCRP limits EVT migration. Bacterial and viral infection results in a decrease in $A B C G 2$ and BCRP in the EVT and a concomitant increase in EVT migration, suggesting that BCRP plays a role in infection-related alterations in EVT function. Such mechanisms may underlie the etiology of pregnancy complications. 


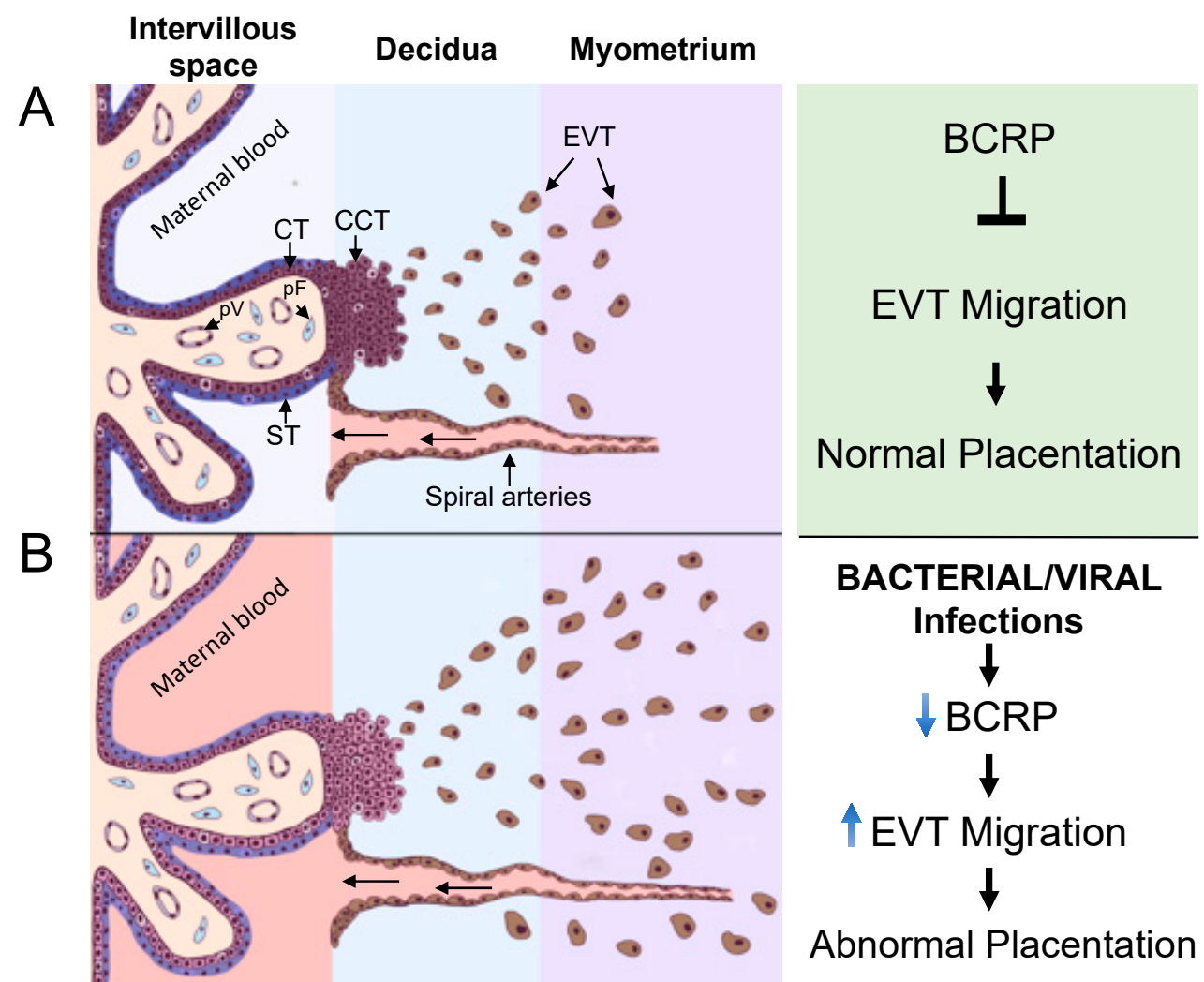

Figure 8. Hypothetical model depicting the impact of bacterial/viral infection mediated downregulation of BCRP on human placentation (A) BCRP decrease cell migration and when disrupted by bacterial and viral infections, (B) may increase EVT migration and lead to abnormal placentation.

Supplementary Materials: The following are available online at http://www.mdpi.com/2073-4409/8/10/1150/s1, Figure S1: Representative Images of cell proliferation assay following siABCG2, scrambled siRNA, Ko143 or VEH exposure at 0 and $24 \mathrm{~h} \mathrm{~N}=6$, Scale bars $=400 \mu \mathrm{m}$. Figure S2: Representative Images of cell proliferation assay following LPS or ssRNA or VEH exposure at 0 and $24 \mathrm{~h}$. $\mathrm{N}=6$, Scale bars $=400 \mu \mathrm{m}$.

Author Contributions: Conception and design: P.L., E.B., L.N., W.G., S.J.L. and S.G.M. Acquisition of the data, analysis, and interpretation of the data: P.L., E.B., L.N., C.P., W.G., S.J.L. and S.G.M. Drafting the article or revising it critically for important intellectual content: P.L., E.B., L.N., C.P., W.G., T.M.O.-C., S.J.L. and S.G.M. Final approval of the version to be published: P.L., E.B., L.N., C.P., W.G., T.M.O.-C., S.J.L. and S.G.M.

Funding: Bill \& Melinda Gates Foundation (OPP1107597), Conselho Nacional de Desenvolvimento Científico e Tecnológico (CNPq; 401605/2013-2), and Canadian Institutes for Health Research (CIHR; FDN-148368).

Acknowledgments: The authors thank the donors and the Research Centre for Women's and Infants' Health BioBank Program, the Lunenfeld-Tanenbaum Research Institute, and the MSH/UHN Dept. of Obstetrics \& Gynecology for the human specimens used in this study (http://biobank.lunenfeld.ca). We also thank Charles Graham for providing the HTR8/SVneo cells and Caroline Dunk for her assistance with placental explants culture. The authors are also thankful to Vanya Peltekova and Ontario Institute for Cancer Research for providing training and access to the Incucyte S3 for this study and Miss Jittanan Nakpu for the illustration in Figure 8.

Conflicts of Interest: The authors declare no conflict of interest.

\section{References}

1. Red-Horse, K.; Zhou, Y.; Genbacev, O.; Prakobphol, A.; Foulk, R.; McMaster, M.; Fisher, S.J. Trophoblast differentiation during embryo implantation and formation of the maternal-fetal interface. J. Clin. Investig. 2004, 114, 744-754. [CrossRef] [PubMed]

2. Pijnenborg, R.; Dixon, G.; Robertson, W.B.; Brosens, I. Trophoblastic invasion of human decidua from 8 to 18 weeks of pregnancy. Placenta 1980, 1, 3-19. [CrossRef] 
3. Lash, G.E.; Otun, H.A.; Innes, B.A.; Percival, K.; Searle, R.F.; Robson, S.C.; Bulmer, J.N. Regulation of extravillous trophoblast invasion by uterine natural killer cells is dependent on gestational age. Hum. Reprod. 2010, 25, 1137-1145. [CrossRef] [PubMed]

4. Brosens, I.; Robertson, W.B.; Dixon, H.G. The physiological response of the vessels of the placental bed to normal pregnancy. J. Pathol. Bacteriol. 1967, 93, 569-579. [CrossRef] [PubMed]

5. Steegers, E.A.; von Dadelszen, P.; Duvekot, J.J.; Pijnenborg, R. Pre-eclampsia. Lancet 2010, 376, 631-644. [CrossRef]

6. Jauniaux, E.; Collins, S.; Burton, G.J. Placenta accreta spectrum: Pathophysiology and evidence-based anatomy for prenatal ultrasound imaging. Am. J. Obstet. Gynecol. 2018, 218, 75-87. [CrossRef]

7. Buca, D.; Liberati, M.; Cali, G.; Forlani, F.; Caisutti, C.; Flacco, M.E.; Manzoli, L.; Familiari, A.; Scambia, G.; D'Antonio, F. Influence of prenatal diagnosis of abnormally invasive placenta on maternal outcome: A systematic review and meta-analysis. Ultrasound Obstet. Gynecol. 2018. [CrossRef]

8. Lurain, J.R. Gestational trophoblastic disease I: Epidemiology, pathology, clinical presentation and diagnosis of gestational trophoblastic disease, and management of hydatidiform mole. Am. J. Obstet. Gynecol. 2010, 203, 531-539. [CrossRef]

9. Bloise, E.; Ortiga-Carvalho, T.M.; Reis, F.M.; Lye, S.J.; Gibb, W.; Matthews, S.G. ATP-binding cassette transporters in reproduction: A new frontier. Hum. Reprod. Update 2016, 22, 164-181. [CrossRef]

10. Lye, P.; Bloise, E.; Dunk, C.; Javam, M.; Gibb, W.; Lye, S.J.; Matthews, S.G. Effect of oxygen on multidrug resistance in the first trimester human placenta. Placenta 2013, 34, 817-823. [CrossRef]

11. Sun, M.; Kingdom, J.; Baczyk, D.; Lye, S.J.; Matthews, S.G.; Gibb, W. Expression of the multidrug resistance P-glycoprotein, (ABCB1 glycoprotein) in the human placenta decreases with advancing gestation. Placenta 2006, 27, 602-609. [CrossRef] [PubMed]

12. Lye, P.; Bloise, E.; Javam, M.; Gibb, W.; Lye, S.J.; Matthews, S.G. Impact of bacterial and viral challenge on multidrug resistance in first- and third-trimester human placenta. Am. J. Pathol. 2015, 185, 1666-1675. [CrossRef] [PubMed]

13. Do Imperio, G.E.; Bloise, E.; Javam, M.; Lye, P.; Constantinof, A.; Dunk, C.; Dos Reis, F.M.; Lye, S.J.; Gibb, W.; Ortiga-Carvalho, T.M.; et al. Chorioamnionitis Induces a Specific Signature of Placental ABC Transporters Associated with an Increase of miR-331-5p in the Human Preterm Placenta. Cell. Physiol. Biochem. 2018, 45, 591-604. [CrossRef] [PubMed]

14. Chen, Z.; Liu, F.; Ren, Q.; Zhao, Q.; Ren, H.; Lu, S.; Zhang, L.; Han, Z. Suppression of ABCG2 inhibits cancer cell proliferation. Int. J. Cancer 2010, 126, 841-851. [CrossRef] [PubMed]

15. Drebert, Z.; MacAskill, M.; Doughty-Shenton, D.; De Bosscher, K.; Bracke, M.; Hadoke, P.W.F.; Beck, I.M. Colon cancer-derived myofibroblasts increase endothelial cell migration by glucocorticoid-sensitive secretion of a pro-migratory factor. Vascul. Pharmacol. 2017, 89, 19-30. [CrossRef] [PubMed]

16. Gong, W.; Wang, Z.; Wan, Y.; Shi, L.; Zhou, Y. Downregulation of ABCG2 protein inhibits migration and invasion in U251 glioma stem cells. Neuroreport 2014, 25, 625-632. [CrossRef] [PubMed]

17. Shi, L.; Wang, Z.; Sun, G.; Wan, Y.; Guo, J.; Fu, X. miR-145 inhibits migration and invasion of glioma stem cells by targeting ABCG2. Neuromol. Med. 2014, 16, 517-528. [CrossRef] [PubMed]

18. Yaguchi, T.; Onishi, T. Estrogen induces cell proliferation by promoting ABCG2-mediated efflux in endometrial cancer cells. Biochem. Biophys. Rep. 2018, 16, 74-78. [CrossRef] [PubMed]

19. Giakoumelou, S.; Wheelhouse, N.; Cuschieri, K.; Entrican, G.; Howie, S.E.; Horne, A.W. The role of infection in miscarriage. Hum. Reprod. Update 2016, 22, 116-133. [CrossRef] [PubMed]

20. Dunk, C.E.; Pappas, J.J.; Lye, P.; Kibschull, M.; Javam, M.; Bloise, E.; Lye, S.J.; Szyf, M.; Matthews, S.G. P-Glycoprotein (P-gp)/ABCB1 plays a functional role in extravillous trophoblast (EVT) invasion and is decreased in the pre-eclamptic placenta. J. Cell. Mol. Med. 2018, 22, 5378-5393. [CrossRef] [PubMed]

21. Genbacev, O.; Schubach, S.A.; Miller, R.K. Villous culture of first trimester human placenta-model to study extravillous trophoblast (EVT) differentiation. Placenta 1992, 13, 439-461. [CrossRef]

22. Lye, P.; Bloise, E.; Nadeem, L.; Gibb, W.; Lye, S.J.; Matthews, S.G. Glucocorticoids modulate multidrug resistance transporters in the first trimester human placenta. J. Cell. Mol. Med. 2018, 22, 3652-3660. [CrossRef] [PubMed]

23. Graham, C.H.; Hawley, T.S.; Hawley, R.G.; MacDougall, J.R.; Kerbel, R.S.; Khoo, N.; Lala, P.K. Establishment and characterization of first trimester human trophoblast cells with extended lifespan. Exp. Cell Res. 1993, 206, 204-211. [CrossRef] [PubMed] 
24. Novembri, R.; Torricelli, M.; Bloise, E.; Conti, N.; Galeazzi, L.R.; Severi, F.M.; Petraglia, F. Effects of urocortin 2 and urocortin 3 on IL-10 and TNF-alpha expression and secretion from human trophoblast explants. Placenta 2011, 32, 969-974. [CrossRef]

25. Potter, J.A.; Garg, M.; Girard, S.; Abrahams, V.M. Viral single stranded RNA induces a trophoblast pro-inflammatory and antiviral response in a TLR8-dependent and -independent manner. Biol. Reprod. 2015, 92, 17. [CrossRef] [PubMed]

26. Javam, M.; Audette, M.C.; Iqbal, M.; Bloise, E.; Gibb, W.; Matthews, S.G. Effect of oxygen on multidrug resistance in term human placenta. Placenta 2014, 35, 324-330. [CrossRef] [PubMed]

27. Livak, K.J.; Schmittgen, T.D. Analysis of relative gene expression data using real-time quantitative PCR and the 2(-Delta Delta C(T)) Method. Methods 2001, 25, 402-408. [CrossRef]

28. Drewlo, S.; Levytska, K.; Kingdom, J. Revisiting the housekeeping genes of human placental development and insufficiency syndromes. Placenta 2012, 33, 952-954. [CrossRef]

29. Imperio, G.E.; Javam, M.; Lye, P.; Constantinof, A.; Dunk, C.E.; Reis, F.M.; Lye, S.J.; Gibb, W.; Matthews, S.G.; Ortiga-Carvalho, T.M.; et al. Gestational age-dependent gene expression profiling of ATP-binding cassette transporters in the healthy human placenta. J. Cell. Mol. Med. 2018. [CrossRef]

30. Wang, F.; Xue, X.; Wei, J.; An, Y.; Yao, J.; Cai, H.; Wu, J.; Dai, C.; Qian, Z.; Xu, Z.; et al. hsa-miR-520h downregulates ABCG2 in pancreatic cancer cells to inhibit migration, invasion, and side populations. Br. J. Cancer 2010, 103, 567-574. [CrossRef]

31. Turner, J.G.; Gump, J.L.; Zhang, C.; Cook, J.M.; Marchion, D.; Hazlehurst, L.; Munster, P.; Schell, M.J.; Dalton, W.S.; Sullivan, D.M. ABCG2 expression, function and promoter methylation in human multiple myeloma. Blood 2006. [CrossRef] [PubMed]

32. Nakanishi, T.; Ross, D.D. Breast cancer resistance protein (BCRP/ABCG2): Its role in multidrug resistance and regulation of its gene expression. Chin. J. Cancer 2012, 31, 73-99. [CrossRef] [PubMed]

33. Miletti-Gonzalez, K.E.; Chen, S.; Muthukumaran, N.; Saglimbeni, G.N.; Wu, X.; Yang, J.; Apolito, K.; Shih, W.J.; Hait, W.N.; Rodriguez-Rodriguez, L. The CD44 receptor interacts with P-glycoprotein to promote cell migration and invasion in cancer. Cancer Res. 2005, 65, 6660-6667. [CrossRef] [PubMed]

34. Toole, B.P.; Slomiany, M.G. Hyaluronan, CD44 and Emmprin: Partners in cancer cell chemoresistance. Drug Res. Updates 2008, 11, 110-121. [CrossRef] [PubMed]

35. Kim, Y.; Kumar, S. CD44-mediated adhesion to hyaluronic acid contributes to mechanosensing and invasive motility. Mol. Cancer Res. 2014, 12, 1416-1429. [CrossRef] [PubMed]

36. Slomiany, M.G.; Dai, L.; Bomar, P.A.; Knackstedt, T.J.; Kranc, D.A.; Tolliver, L.; Maria, B.L.; Toole, B.P. Abrogating drug resistance in malignant peripheral nerve sheath tumors by disrupting hyaluronan-CD44 interactions with small hyaluronan oligosaccharides. Cancer Res. 2009, 69, 4992-4998. [CrossRef] [PubMed]

37. Goodison, S.; Urquidi, V.; Tarin, D. CD44 cell adhesion molecules. Mol. Pathol. 1999, 52, 189-196. [CrossRef]

38. Takahashi, H.; Takizawa, T.; Matsubara, S.; Ohkuchi, A.; Kuwata, T.; Usui, R.; Matsumoto, H.; Sato, Y.; Fujiwara, H.; Okamoto, A.; et al. Extravillous trophoblast cell invasion is promoted by the CD44-hyaluronic acid interaction. Placenta 2014, 35, 163-170. [CrossRef]

39. Lu, Y.C.; Yeh, W.C.; Ohashi, P.S. LPS/TLR4 signal transduction pathway. Cytokine 2008, 42, 145-151. [CrossRef]

40. Petrovic, V.; Wang, J.H.; Piquette-Miller, M. Effect of endotoxin on the expression of placental drug transporters and glyburide disposition in pregnant rats. Drug Metab. Dispos. 2008, 36, 1944-1950. [CrossRef]

41. Bloise, E.; Bhuiyan, M.; Audette, M.C.; Petropoulos, S.; Javam, M.; Gibb, W.; Matthews, S.G. Prenatal endotoxemia and placental drug transport in the mouse: Placental size-specific effects. PLoS ONE 2013, 8, e65728. [CrossRef] [PubMed]

42. Yamamoto, M.; Sato, S.; Hemmi, H.; Hoshino, K.; Kaisho, T.; Sanjo, H.; Takeuchi, O.; Sugiyama, M.; Okabe, M.; Takeda, K.; et al. Role of adaptor TRIF in the MyD88-independent toll-like receptor signaling pathway. Science 2003, 301, 640-643. [CrossRef] [PubMed]

43. Bloise, E.; Petropoulos, S.; Iqbal, M.; Kostaki, A.; Ortiga-Carvalho, T.M.; Gibb, W.; Matthews, S.G. Acute Effects of Viral Exposure on P-Glycoprotein Function in the Mouse Fetal Blood-Brain Barrier. Cell. Physiol. Biochem. 2017, 41, 1044-1050. [CrossRef] [PubMed]

44. Goertz, G.P.; Abbo, S.R.; Fros, J.J.; Pijlman, G.P. Functional RNA during Zika virus infection. Virus Res. 2018, 254, 41-53. [CrossRef] [PubMed] 
45. Davis, M.; Sagan, S.M.; Pezacki, J.P.; Evans, D.J.; Simmonds, P. Bioinformatic and physical characterizations of genome-scale ordered RNA structure in mammalian RNA viruses. J. Virol. 2008, 82, 11824-11836. [CrossRef] [PubMed]

46. Petersen, L.R.; Jamieson, D.J.; Honein, M.A. Zika Virus. N. Engl. J. Med. 2016, 375, 294-295. [CrossRef] [PubMed]

47. Saiz, J.C.; Martin-Acebes, M.A.; Bueno-Mari, R.; Salomon, O.D.; Villamil-Jimenez, L.C.; Heukelbach, J.; Alencar, C.H.; Armstrong, P.K.; Ortiga-Carvalho, T.M.; Mendez-Otero, R.; et al. Zika Virus: What Have We Learnt Since the Start of the Recent Epidemic? Front. Microbiol. 2017, 8, 1554. [CrossRef] [PubMed]

48. Luo, H.; Winkelmann, E.R.; Fernandez-Salas, I.; Li, L.; Mayer, S.V.; Danis-Lozano, R.; Sanchez-Casas, R.M.; Vasilakis, N.; Tesh, R.; Barrett, A.D.; et al. Zika, dengue and yellow fever viruses induce differential anti-viral immune responses in human monocytic and first trimester trophoblast cells. Antivir. Res. 2018, 151, 55-62. [CrossRef]

49. Noronha, L.d.; Zanluca, C.; Burger, M.; Suzukawa, A.A.; Azevedo, M.; Rebutini, P.Z.; Novadzki, I.M.; Tanabe, L.S.; Presibella, M.M.; Duarte dos Santos, C.N. Zika Virus Infection at Different Pregnancy Stages: Anatomopathological Findings, Target Cells and Viral Persistence in Placental Tissues. Front. Microbiol. 2018, 9. [CrossRef]

50. Lyall, F.; Bulmer, J.N.; Duffie, E.; Cousins, F.; Theriault, A.; Robson, S.C. Human trophoblast invasion and spiral artery transformation: The role of PECAM-1 in normal pregnancy, preeclampsia, and fetal growth restriction. Am. J. Pathol. 2001, 158, 1713-1721. [CrossRef]

51. Nourollahpour Shiadeh, M.; Behboodi Moghadam, Z.; Adam, I.; Saber, V.; Bagheri, M.; Rostami, A. Human infectious diseases and risk of preeclampsia: An updated review of the literature. Infection 2017, 45, 589-600. [CrossRef] [PubMed]

(C) 2019 by the authors. Licensee MDPI, Basel, Switzerland. This article is an open access article distributed under the terms and conditions of the Creative Commons Attribution (CC BY) license (http://creativecommons.org/licenses/by/4.0/). 